\title{
Multidrug Resistance Process
}

National Cancer Institute

\section{Source}

National Cancer Institute. Multidrug Resistance Process. NCI Thesaurus. Code C17745.

Simultaneous resistance to a spectrum of unrelated drugs following exposure to a single agent. Mechanisms involve expression of multidrug efflux pumps (p-glycoprotein), altered glutathione metabolism, decreased topoisomerase II activity, and changes in various cellular proteins. 